\title{
Selection of reference genes for quantitative real-time PCR analysis in cucumber (Cucumis sativus L.), pumpkin (Cucurbita moschata Duch.) and cucumber-pumpkin grafted plants
}

\author{
Li Miao ${ }^{1,2}$, Xing Qin ${ }^{3}$, Lihong Gao ${ }^{2}$, Qing Li ${ }^{1}$, Shuzhen $\mathrm{Li}^{1}{ }^{\text {, }}$ Chaoxing He ${ }^{1}$, Yansu Li ${ }^{\text {Corresp., }}{ }^{1}$, Xianchang \\ Yu $\mathbf{u}^{\text {Corresp. } 1}$ \\ 1 Institute of Vegetables and Flowers, Chinese Academy of Agricultural Sciences, Beijing, China \\ 2 Beijing Key Laboratory of Growth and Developmental Regulation for Protected Vegetable Crops, College of Horticulture, China Agricultural University, \\ Beijing, China \\ 3 Agricultural Genomics Institute at Shenzhen, Chinese Academy of Agricultural Sciences, Shenzhen, China \\ Corresponding Authors: Yansu Li, Xianchang Yu \\ Email address: liyansu@caas.cn, yuxianchang@caas.cn
}

Background: Quantitative real-time PCR (qRT-PCR) is a commonly used high-throughput technique to measure mRNA transcript levels. The accuracy of this evaluation of gene expression depends on the use of optimal reference genes. Cucumber-pumpkin grafted plants, made by grafting a cucumber scion onto pumpkin rootstock, are superior to either parent plant, as grafting conveys many advantages. However, although many reliable reference genes have been identified in both cucumber and pumpkin, none have been obtained for cucumber-pumpkin grafted plants.

Methods: In this work, 12 candidate reference genes, including 8 traditional genes and 4 novel genes identified from our transcriptome data, were selected to assess their expression stability. Their expression levels in 25 samples, including 3 cucumber and 3 pumpkin samples from different organs, and 19 cucumber-pumpkin grafted samples from different organs, conditions, and varieties, were analyzed by qRT-PCR, and the stability of their expression was assessed by the comparative $\Delta$ Ct method, geNorm, NormFinder, BestKeeper, and RefFinder.

Results: The results showed that the most suitable reference gene varied dependent on the organs, conditions, and varieties. CACS and 40SRPS8 were the most stable reference genes for all samples in our research. TIP41 and CACS showed the most stable expression in different cucumber organs, TIP41 and PP2A were the optimal reference genes in pumpkin organs, and CACS and 40SRPS8 were the most stable genes in all grafted cucumber samples. However, the optimal reference gene varied under different conditions. CACS and 40SRPS8 were the best combination of genes in different organs of cucumber-pumpkin grafted plants, TUA and RPL36Aa were the most stable in the graft union under cold stress, LEA26 and ARF showed the most stable expression in the graft union during the healing process, and TIP41 and PP2A were the most stable across different varieties of cucumber-pumpkin grafted plants. The use of $L E A 26, A R F$ and $L E A 26+A R F$ as reference genes were further verified by analyzing the expression levels of $C S a C Y C D 3 ; 1, C S a R U L, C M O R U L$, and $C m o P I N$ in the graft union at different time points after grafting.

Discussion: This work is the first report of appropriate reference genes in grafted cucumber plants and provides useful information for the study of gene expression and molecular mechanisms in cucumber-pumpkin grafted plants. 


\section{Selection of reference genes for quantitative real-time PCR analysis}

\section{2 in cucumber (Cucumis sativus L.), pumpkin (Cucurbita moschata}

3 Duch.) and cucumber-pumpkin grafted plants

4

5

6

7

\section{Li Miao', ${ }^{1,2}$ Xing Qin ${ }^{3}$, Lihong $\mathrm{Gao}^{2}$, Qing $\mathrm{Li}^{1}$, Shuzhen $\mathrm{Li}^{1}$, Chaoxing $\mathrm{He}^{1}$, Yansu Li ${ }^{1}$,} Xianchang $\mathbf{Y u}^{1}$

${ }^{1}$ Institute of Vegetables and Flowers, Chinese Academy of Agriculture Sciences, Beijing, China

${ }^{2}$ Beijing Key Laboratory of Growth and Developmental Regulation for Protected Vegetable Crops, College of Horticulture, China Agricultural University, Beijing, China

${ }^{3}$ Agricultural Genomics Institute at Shenzhen, Chinese Academy of Agricultural Sciences, Shenzhen, China

Corresponding Author: Yansu Li, Xianchang Yu No.12 South Avenue Zhongguan Park Beijing, Haidian district, Beijing100081, China Email address: liyansu@caas.cn; yuxianchang@caas.cn

\section{Abstract}

Background: Quantitative real-time PCR (qRT-PCR) is a commonly used high-throughput technique to measure mRNA transcript levels. The accuracy of this evaluation of gene expression depends on the use of optimal reference genes. Cucumber-pumpkin grafted plants, made by grafting a cucumber scion onto pumpkin rootstock, are superior to either parent plant, as grafting conveys many advantages. However, although many reliable reference genes have been identified in both cucumber and pumpkin, none have been obtained for cucumber-pumpkin grafted plants.

Methods: In this work, 12 candidate reference genes, including 8 traditional genes and 4 novel genes identified from our transcriptome data, were selected to assess their expression stability. Their expression levels in 25 samples, including 3 cucumber and 3 pumpkin samples from different organs, and 19 cucumber-pumpkin grafted samples from different organs, conditions, and varieties, were analyzed by qRT-PCR, and the stability of their expression was assessed by the comparative $\Delta \mathrm{Ct}$ method, geNorm, NormFinder, BestKeeper, and RefFinder.

Results: The results showed that the most suitable reference gene varied dependent on the organs, conditions, and varieties. CACS and 40SRPS 8 were the most stable reference genes for all samples in our research. TIP41 and CACS showed the most stable expression in different cucumber organs, TIP41 and $P P 2 A$ were the optimal reference genes in pumpkin organs, and $C A C S$ and 40SRPS8 were the most stable genes in all grafted cucumber samples. However, the optimal reference gene varied under different conditions. CACS and 40SRPS 8 were the best combination of genes in different organs of cucumber-pumpkin grafted plants, TUA and 
38

39

40

41

42

43

44

45

46

47

48

49

50

51

52

53

54

55

56

57

58

59

60

61

62

63

64

65

66

67

68

69

70

71

72

73

74

75

76

77

RPL36Aa were the most stable in the graft union under cold stress, $L E A 26$ and $A R F$ showed the most stable expression in the graft union during the healing process, and TIP41 and PP2A were the most stable across different varieties of cucumber-pumpkin grafted plants. The use of $L E A 26, A R F$ and $L E A 26+A R F$ as reference genes were further verified by analyzing the expression levels of $c s a C Y C D 3 ; 1, c s a R U L, c m o R U L$, and $c m o P I N$ in the graft union at different time points after grafting.

Discussion: This work is the first report of appropriate reference genes in grafted cucumber plants and provides useful information for the study of gene expression and molecular mechanisms in cucumber-pumpkin grafted plants.

\section{Introduction}

Cucumber (Cucumis sativus L.) is one of the most widely cultivated vegetable crops in the world. Grafted cucumber plants are popular due to their greater resistance to soil-borne diseases, increased tolerance to abiotic stress, improved mineral nutrition uptake and use, and increased fruit yield and quality (Huang et al., 2014). A cucumber scion is typically grafted onto pumpkin (Cucurbita moschata Duch.) rootstock (Lee et al., 2010; Huang et al., 2014). Grafting conveys advantages over the properties of each individual parent plant, but the resulting plant is also more complex than the parents. The graft union is the successful combination of the scion and rootstock, allowing the establishment of complex communication between rootstock and scion. There have been many physiological and biochemical studies of cucumber-pumpkin grafted plants (Ahn et al., 1999; Yang et al., 2006; Haroldsen et al., 2012; Li et al., 2014), however, there have been few studies analyzing gene function, transcription, or expression in cucumberpumpkin grafted plants, as few pumpkin genes were identified. Now, the entire cucumber (http://cucurbitgenomics.org/organism/2) (Huang et al., 2009) and pumpkin (http://cucurbitgenomics.org/organism/9) (Sun et al., 2017) genomes have been published, enabling further studies on the molecular biology of these species.

Gene expression analysis is fundamental to elucidate the molecular mechanisms underlying various biological processes (Bustin et al., 2005), and qRT-PCR is the most common technique used to study gene expression because of its high sensitivity, accuracy, specificity, costeffectiveness, and reproducibility (Bustin et al., 2002; Nolan et al., 2006; Derveaux et al., 2010). However, non-specific variations can cause errors resulting in unreliability of the qRT-PCR data, such as variability in RNA quality, cDNA synthesis and concentration, PCR procedures, and efficiency of amplification (Delporte et al., 2015). To avoid these problems in analyzing results, stable reference genes should be used to normalize the gene expression data. Appropriate reference genes should be systematically evaluated across various environments (varieties, tissues, experimental treatments, and developmental stages) before being used as controls in qRT-PCR analysis (Bustin et al., 2009; Guenin et al., 2009; Sgamma et al., 2016). However, there are no previous reports of systematic studies performed on grafted cucumber plants to determine reliable reference genes. Common reference genes like ACT (actin), TUA (tubulin), CYP (cyclophilin), UBI-1 (ubiquitin), and $E F-\alpha$ (elongation factor) are considered to be stably expressed in most plants (Duan et al., 
2017; Obrero et al., 2011; Tashiro et al., 2016; Niu et al., 2017) and have been used for gene expression studies in cucumber (Wang et al., 2009; Migocka and Papierniak, 2011; Warzybock and Migocka, 2013). The genes UFP (ubiquitin), EF-1A (elongation factor), PRL36aA (60S ribosomal protein L36a/L44), PP2A (protein phosphatase) and CACS (clathrin adaptor complexes medium submit family protein) have been used for reliable normalization in different experimental sets in zucchini (Cucurbita pepo) (Obrero et al., 2011), and these reference genes have been successfully applied to both cucumber and pumpkin in specific environments, including powdery mildew, salinity, cold, dehydration, $\mathrm{H}_{2} \mathrm{O}_{2}$, and abscisic acid (ABA) treatments (Berg et al., 2015; Cao et al., 2017; Reda et al., 2018). Unfortunately, no single reference gene has been confirmed that exhibits uniform and stable expression under different experimental conditions. For example, $A C T$ is a frequently used reference genes in many plants, but showed variant expression during short-term treatment of cucumber with salt, osmotic, or oxidative stress (Migocka and Papierniak, 2011). Overall, it is necessary to identify one or more reference genes that show stable expression under different experimental conditions prior to carrying out gene expression studies (Duan et al., 2017).

In this study, traditional reference genes from published research and new genes based upon their coefficients of variation (CVs) and expression intensity in our RNA-seq data from cucumberpumpkin grafted plants at different stages were selected for further analysis. Twelve genes were investigated in this study, eight commonly used reference genes, ACT, CYP, CACS, TUA, TIP41 (tonoplast intrinsic protein), F-Box (F-box protein), RPL36Aa, and PP2A, and four new genes identified by RNA-seq analysis, UBC (Ubiquitin conjugating enzyme), ARF (ADP-ribosylation factor-like protein), LEA26 (Late-embryogenesis abundant protein 26), and 40SRPS8 (40S ribosomal protein $S 8)$. These twelve genes were evaluated to validate their use as stable reference genes for qRT-PCR in different organs, at different stages, in different varieties, and under stress conditions in cucumber, pumpkin, and cucumber-pumpkin grafted plants. To determine the appropriate reference genes, four statistical tools were used to evaluate the accuracy of these candidate genes: the $\Delta \mathrm{Ct}$ method (Silver et al., 2006), geNorm (Vandesompele et al., 2002), NormFinder (Andersen et al., 2004), and BestKeeper (Pfaffl et al., 2004). Comprehensive stability rankings were generated by RefFinder (Xie et al., 2012). Additionally, the expression of $C Y C D 3 ; 1, R U L$ and PIN, genes that are thought to be related to graft union healing in Arabidopsis (Melnyk et al., 2018), were investigated as a case study to evaluate the effectiveness of the reference genes identified in this study. The results obtained in this study will be useful in future gene expression analyses in cucumber, pumpkin, and their grafted plants.

\section{Materials \& Methods}

\section{Plant Materials and Treatments}

Cucumber (Cucumis sativus L.) and pumpkin (Cucurbita moschata Duch.) were planted in an artificial chamber at the farm of the Institute of Vegetables and Flowers, Chinese Academy of Agricultural Sciences, Beijing, China at a temperature of $28^{\circ} \mathrm{C} / 20^{\circ} \mathrm{C}$ (day/night) with a photoperiod cycle of $12 / 12 \mathrm{~h}$ and $60 \%-70 \%$ relative humidity. Cucumber variety 'Zhongnong No. 26' was used as the scion and pumpkin variety 'Jinxinzhen No. 5' was used as the rootstock. 
118 Seeds of the scion and rootstock were sown in 50 -cell $\left(55 \mathrm{~cm}^{3} /\right.$ cell $)$ and 32 -cell $\left(32 \mathrm{~cm}^{3} /\right.$ cell $)$

119 polystyrene trays, respectively, containing commercial organic substrates

120 (Vpeatmoss:Vvermiculite:Vperlite $=1: 1: 1$ ). The environmental conditions for germination were

$12125-28^{\circ} \mathrm{C}$ and $85 \%-90 \%$ relative humidity. The pumpkin seeds were sown three days before the

122 cucumber seeds. When cotyledons of the scion were fully open and the first true leaf of the

123 rootstock started to develop (9-10 d after sowing), the plants were grafted using the hole

124 insertion grafting method as previously described (Miao et al., 2018) (Fig S1). Autografts were

125 carried out for both cucumber and pumpkin, as well as cucumber-pumpkin heterografts. The

126 grafted seedlings were maintained at a temperature of $30^{\circ} \mathrm{C} / 22^{\circ} \mathrm{C}$ (day/night), a constant

127 humidity of $95 \%-100 \%$ and a dim light of 50 PPFD for the first 5 days, then the light density

128 was slowly increased from 50 to 500 PPFD and the humidity was decreased from $95 \%$ to $60 \%$,

129 while the other environmental conditions were unchanged. For the autograft cucumber and

130 pumpkin plants, samples of the leaves, stems and roots were harvested when the seedlings had

131 two true leaves. For cucumber grafted onto pumpkin, samples of the leaves, the stem of the

132 scion, the graft union (Fig 1), the stem of the rootstock, and the roots were harvested. For the cold

133 stress experiment, when the grafted cucumber had two leaves, seedlings were exposed to

134 temperatures of $12^{\circ} \mathrm{C}$ in a chamber, and samples of the graft union were harvested at $0,5,12$ and

$13524 \mathrm{~h}$ of stress treatment. To investigate the graft union healing process, samples of the graft

136 union were harvested 0, 3, 6, 9 and $15 \mathrm{~d}$ after grafting. For experiments with varieties, cucumber

137 varieties 'Xintaimici' and 'Zhongnong No. 26' were used as scions and pumpkin varieties

138 'Zhongguonangua No. 26', 'Jinxinzhen No. 5' and 'Huofenghuang' were used as rootstocks. The 139 graft combinations were 'Xintaimici-Zhongguonangua No. 26', 'Xintaimici-Jinxinzhen No. 5',

140 'Xintaimici-Huofenghuang', 'Zhongnong No. 26-Jinxinzhen No. 5', and 'Zhongnong No.26-

141 Huofenghuang'. Graft unions were harvested when grafted plants had two true leaves. For each

142 treatment, three independent biological replicates were achieved. All samples were immediately

143 frozen in liquid nitrogen and stored at $-80^{\circ} \mathrm{C}$.

144 RNA Isolation and cDNA Synthesis

145 The RNAprep Pure Plant Plus Kit (Tiangen, Beijing, China) was used for total RNA extraction.

146 Genomic DNA was eliminated from the total RNA using RNase-free DNase I. The RNA

147 integrity was confirmed by $1.0 \%$ agarose gel electrophoresis. RNA concentrations were

148 determined by NanoDrop ${ }^{\text {TM }} 2000$ spectrophotometer (Thermo Scientific, Waltham, MA, USA),

149 samples with an A260/A280 ratio of 1.8-2.2 and an A260/A230 ratio > 2.0 were used for further

150 analyses. First-strand cDNA synthesis was performed using a FastQuant cDNA Synthesis kit

151 (Tiangen, Beijing, China) according to the manufacturer's instructions.

152 Candidate Reference Gene Selection and Primer Design

153 Eight commonly used reference genes (ACT, CYP, CACS, TUA, TIP41, F-Box, PRL36Aa and

$154 P P 2 A)$ from published studies on cucumber, pumpkin, chicory, buckwheat, lettuce and mangrove

155 tree were selected (Wan et al., 2010; Obrero et al., 2011; Delporte et al., 2015; Demidenko et al.

156 2011; Borowski et al., 2014; Saddhe et al., 2018). For new candidate reference genes, we

157 analyzed our transcriptomic data from the graft union. Graft union of cucumber-pumpkin were 
158

159

160

161

162

163

164

165

166

167

168

169

170

171

172

173

174

175

176

177

178

179

180

181

182

183

184

185

186

187

188

189

190

191

192

193

194

195

196

197

respectively harvested at $0,3,6,9$ days after grafting, three biological replicates were performed for each time point. In total 18 transcriptome libraries, $132.7 \mathrm{G}$ raw reads were obtained, at the least $91.4 \%$ of the reads were mapped to the reference sequence, and assemble into 32,852 and 47,906 transcripts of cucumber and pumpkin, respectively. 20,782 unigene of cucumber with the average length of $4.1 \mathrm{~kb}$ were obtained, while 27,187 unigene with average length of $4.4 \mathrm{~kb}$ were generated (Table S1). The genes with the most constant expression levels were defined as candidate reference genes (De Jong et al., 2007). We calculated the mean expression value, standard deviation, and coefficients of variation (CVs) based on the raw RNA-seq data, and CVs $=$ standard deviation of RPKM/average of RPKM. Based on the requirements $\mathrm{CV} \leq 0.2$ and $300 \leq \mathrm{RPKM} \leq 500$ (Duan et al., 2017), we selected new reference genes by removing overabundant genes with low expression levels. With requirements of evalue e-5, we used BLAST (Basic Local Alignment Search Tool) to determine the proteins encoded by cucumber and pumpkin genes, respectively (https://blast.ncbi.nlm.nih.gov/Blast.cgi), and then filtered the BLAST results based on an identity $\geq 90$ and an overlap ratio $>0.5$ (between query and target).

This resulted in ten and seven genes of cucumber and pumpkin, respectively, which may be suitable as reference genes. A comparison of the relationship between cucumber and pumpkin by homology analysis is shown in Table S2. Finally, UBC, ARF, LEA26 and 40SRPS8 were selected as candidate reference genes based on preliminary experiments of single PCR product in agarose gel electrophoresis ( Fig S2). Based on the conserved sequence of these genes between cucumber and pumpkin, primers were designed using Primer Premier 5.0 software with the following parameters: a melting temperature $(\mathrm{Tm})$ of $50-60^{\circ} \mathrm{C}$, a primer length of $17-25 \mathrm{bp}$, and a product size of 70-260 bp (http://www.premierbiosoft.com/) (Table 1). Amplification of a single PCR product in $1 \%$ agarose gel electrophoresis and a single peak of the melting curve in qRT-PCR were used to ensure the specificity of the primers for the candidate reference genes.

\section{qRT-PCR Assay}

qRT-PCR was performed on an Agilent Stratagene Mx3000P Real-Time PCR machine (Agilent Stratagene, USA) using SYBR ${ }^{\circledR}$ Premix Ex Taq ${ }^{\mathrm{TM}}$ (TliRNaseH Plus) (TaKaRa, Dalian, China). Each $20 \mu 1$ reaction mixture contained $2 \mu 1$ of cDNA template, $0.4 \mu 1$ of each primer, $0.4 \mu 1$ of ROX dye, $10 \mu 1$ of $2 \times$ SYBR Premix Ex Taqand $6.8 \mu 1$ of $\mathrm{ddH}_{2} \mathrm{O}$. The qRT-PCR reaction conditions were as follows: $94^{\circ} \mathrm{C}$ for $30 \mathrm{~s}, 40$ cycles of $94^{\circ} \mathrm{C}$ for $5 \mathrm{~s}$, then $60^{\circ} \mathrm{C}$ for $34 \mathrm{~s}$. A melting curve was determined by increasing the amplification temperature from $60-95^{\circ} \mathrm{C}$, with a temperature increment of $0.5^{\circ} \mathrm{C}$ every $5 \mathrm{~s}$. All samples were performed with three technical replicates, and samples without template were used as a control. The amplification efficiencies for each primer and the regression coefficients $\left(\mathrm{R}^{2}\right)$ were evaluated using five-fold dilutions of pooled cDNA $(1 / 5,1 / 25,1 / 125,1 / 625,1 / 3125)$ that were diluted using EASY dilution solution (Takara, Japan).

\section{Gene Expression Stability Analysis}

To evaluate the expression levels of each reference gene, we drew boxplots of the $\mathrm{Ct}$ values for the 12 candidate reference genes. Four statistical tools, the $\Delta \mathrm{Ct}$ method (Silver et al., 2006), geNorm (Vandesompele et al., 2002), NormFinder (Andersen et al., 2004), and BestKeeper 
198

199

200

201

202

203

204

205

206

207

208

209

210

211

212

213

214

215

216

217

218

219

220

221

222

223

224

225

226

227

228

229

230

231

232

233

234

235

236

237

(Pfaffl et al., 2004), were used to evaluate the stability of the 12 candidate reference genes at various treatment durations. The raw $\mathrm{Ct}$ values of the reference genes were transformed into the correct input files according to the requirements of the software. Finally, a comprehensive ranking of the reference genes was generated using RefFinder (Duan et al., 2017).

\section{Validation of Reference Gene Stability}

To confirm the reliability of the selected reference genes, the relative expression levels of three genes involved in xylem development were measured during graft union healing in grafted cucumbers (Table S3). Samples of the graft union of cucumber-pumpkin grafted plants were harvested at $0,1,3,6,9$ and $15 \mathrm{~d}$ after grafting. The most stable reference genes ( $L E A 26, A R F$ and $L E A 26+A R F)$, and the least stable reference gene $(P P 2 A)$ ranked by RefFinder were used for normalization. Comparative gene expression levels of csaCYCD3;1 (Csa2G356610), csaRUL (Csa3G895630), cmoRUL (CmoCh15G013320) and cmoPIN (CmoCh15G009810) were calculated using the $2^{-\Delta \Delta C t}$ method. Three technical replicates were performed for each biological sample.

\section{Results}

\section{Evaluation of Primer Specificity and Amplification Efficiency}

To validate the primer specificity of the 12 candidate reference genes in our study, the specificity of the PCR reactions was subjected to 1\% agarose gel electrophoresis (Fig S2). The product lengths were consistent with the expected lengths, and a single sharp peak was observed in the melting curves for cucumber, pumpkin, and grafted cucumber (Fig S3, S4A). Additionally, the amplification efficiency (E) ranged from 0.86 to 1.13 , with the correlation coefficients $\left(\mathrm{R}^{2}\right)$ of the standard curve varying from 0.986 to 0.999 (Table 1, Fig S4B, S5).

\section{Expression Levels and Variations in Candidate Reference Genes}

The transcript abundances of the 12 candidate reference genes were assessed based on the $\mathrm{Ct}$ values from the qRT-PCR for different kinds of samples. As shown in Fig 2, the Ct values for the 12 candidate reference genes ranged from 16.98 to 31.71 , and the mean $\mathrm{Ct}$ values were 19.04, 18.35, 23.26, 20.80, 20.66, 26.70, 20.79, 24.79, 20.26, 21.78, 20.8 and 21.09 for $A C T$, CYP, CACS, TUA, TIP41, F-Box, PRL36Aa, PP2A, UBC, ARF, LEA26 and 40SRPS8, respectively.

\section{Expression Stability Analysis of Candidate Reference Genes}

The stabilities of the 12 candidate reference genes in our study were evaluated separately using the $\Delta \mathrm{Ct}$ method, geNorm, NormFinder, BestKeeper, and RefFinder. The 12 candidate reference genes were divided into eight groups of different treatments: organs of cucumber, pumpkin, and cucumber-pumpkin grafted plants under normal conditions were termed Cos, Pos, and Gos, respectively. Graft union samples under low temperatures were termed GLgs, graft union samples during the healing process were termed Ggs, graft union samples of different varieties of cucumber-pumpkin grafted plants were termed Ggvs, all cucumber-pumpkin grafted plant samples were termed GoAll, and all samples in our study were termed All.

$\Delta \mathbf{C t}$ method analysis. The $\Delta \mathrm{Ct}$ method ranks the stability of expression of tested genes by comparing the relative expression of gene pairs within each sample (Silver et al., 2006). As 
238 shown in Table 2, TIP41 was the most stable reference gene in the Cos, Pos, and Ggvs samples, 239 while TIP41 was the lowest stable reference gene in the GLgs samples. CACS was the most 240 stable reference gene in the Gos, GoAll, and All samples, and TUA and LEA26 were ranked as 241 the most stable reference genes in the GLgs and Ggs samples, respectively (Table 2, S4).

242 BestKeeper analysis. The BestKeeper program identifies potential reference genes by 243 calculating the coefficients of variation (CVs) and the standard deviation (SD) of the $\mathrm{Ct}$ values, 244 where lower CVs and SD indicate higher stability (Pfaffl et al., 2004). For the Cos and GoAll 245 samples, $C A C S$ was identified as the most stable gene, and TIP41 was the most stable gene in the 246 Pos and Ggvs samples. $C Y P$ was the most stable gene in the Gos samples, but was the lowest 247 ranking gene in the Ggvs samples. Similarly, TUA was the most stable gene in the GLgs 248 samples, but was the lowest stable gene in the Pos samples. ARF and LEA26 were ranked as the 249 most stable reference gene in the Ggs and All samples, respectively. PP2A was the reference 250 251 gene with the lowest stability in most samples, including the Gos, Ggs, GoAll, and All samples (Table 2, S4).

NormFinder analysis. NormFinder ranks the stability of tested genes based on inter- and intragroup variations in expression across different sample groups, and lower values indicate higher stability (Andersen et al., 2004). TIP41 had stability values of $0.084,0.153$, and 0.203 , making it the most stable gene in the Cos, Pos, and Ggvs samples, respectively. 40SRPS 8 and $C A C S$ were the two most stable genes and $P P 2 A$ was the gene with the lowest stability in the Gos, GoAll, and All samples. For the GLgs samples, TUA was the most stable, but was ranked as the lowest stability reference gene in the Pos samples. The stability of LEA26 was best in the Ggs samples (Table 2, S4).

geNorm analysis. The geNorm software determines gene expression stability using M-values based on the average pairwise variation of all candidate genes (Vandesompele et al., 2002). TIP4I and 40SRPS8, CACS and ARF, CYP and UBC, UBC and ARF, PP2A and ARF, ARF and 40SPRS8, were the two most stable genes in the Cos, Gos, GLgs, Ggs, Ggvs, and GoAll samples, respectively. CACS and 40SRPS 8 were identified as the most stable reference genes with Mvalues of 0.093 and 0.582 in the Pos and All samples, respectively (Table 2, S4). In addition, the optimal number of reference genes was determined using the geNorm algorithm based on pairwise variation $(\mathrm{Vn} / \mathrm{Vn}+1)$. A value of $\mathrm{Vn} / \mathrm{Vn}+1<0.15$ indicates that the optimal number of reference genes equal to a value of $\mathrm{n}$ is sufficient for its use as a reference gene (Vandesompele et al., 2002). In our study, the values of $V_{2} / V_{3}$ of all experimental samples were less than 0.15 , which indicated that two reference genes would be sufficient for gene normalization under these experimental conditions (Fig 3).

RefFinder analysis. RefFinder considers the results from the $\Delta \mathrm{Ct}$ method, geNorm, NormFinder and BestKeeper to provide a comprehensive ranking of the most stable genes (Xie et al., 2012). TIP41 was the most stable reference gene in the Cos, Pos, and Ggvs samples, CACS was ranked as the most stable gene in the Gos, GoAll, and All samples. TUA was the most stable in the GLgs samples, but was also the lowest reference gene in the Pos samples. $L E A 26$ and $A R F$ were the 
277 two most stable reference genes in the Ggs samples. PP2A was the lowest stable reference gene

278 in the Gos, Ggs, GoAll, and All samples (Table 2, S4).

279 Validation of the Selected Reference Genes

280 To confirm the stability of the selected reference genes, the expression levels of four graft union 281 healing-related genes were examined by normalization to the levels of $L E A 26, A R F$,

$282 L E A 26+A R F$, and $P P 2 A$ as reference genes (Table S3). RefFinder analysis showed that $L E A 26$

283 and $A R F$ were the most suitable reference genes and $P P 2 A$ was the least suitable reference gene

284 in the graft union during the healing process (Table 2, S4).

285 The expression patterns of csaCYCD3;1, csaRUL, cmoRUL, and cmoPIN showed similar

286 changes when $L E A 26, A R F$, or $L E A 26+A R F$ were selected as the reference genes for

287 normalization (Fig 4). The expression levels of $c s a C Y C D$ and $c s a R U L$ were significantly

288 downregulated at $3 \mathrm{~d}$ and $6 \mathrm{~d}$ compared to $1 \mathrm{~d}$ after grafting. However, these values were

289 markedly higher when $P P 2 A$ was selected for normalization. Compared with the sample 0 day

290 after grafting, $c m o P I N$ expression was clearly downregulated at the graft junction at $6 \mathrm{~d}, 9 \mathrm{~d}$, and

$29115 \mathrm{~d}$ after grafting when using $L E A 26, A R F$, or $L E A 26+A R F$ as reference genes, butthe

292 expression pattern was completely different when $P P 2 A$ was used as a reference. Similarly,

293 compared with the sample 0 day after grafting, cmoRUL expression levels increased 3.99, 3.31,

294 and 3.43 times at the graft junction 3 days after grafting when using $L E A 26, A R F$, and

$295 L E A 26+A R F$ as reference genes, respectively, but the change in expression was calculated as a

296 12.70-fold increase if the level of $P P 2 A$ was used for transcript normalization.

\section{Discussion}

298 qRT-PCR is a powerful method for detecting transcriptomic data and studying underlying

299 molecular mechanisms (Niu et al., 2017). Appropriate reference genes are required to ensure the

300 accuracy of qRT-PCR results. There has been research into the selection of optimal reference

301 genes in cucumber and pumpkin (Wan et al., 2010; Obrero et al., 2011; Warzybock and

302 Migocka, 2013), however, there have been no studies on the selection of the optimal reference

303 genes for cucumber-pumpkin grafted plants. Grafting assembles the scion and rootstock into a

304 plant with advantages over the parent plants. This is significant exchange of materials between

305 scion and rootstock, includingwater, sugars, hormones, RNAs, and proteins (Melnyk, 2017), so it

306 is highly likely that the optimal reference genes for cucumber-pumpkin grafted plants may differ

307 from the optimal reference genes for cucumber or pumpkin. To test this, we selected some

308 commonly used reference genes that are previously published ( $A C T, C Y P, C A C S, T U A, T I P 41$,

$309 F$-Box, PRL36Aa and $P P 2 A)$ and are known to be expressed in cucumber or pumpkin. We also

310 selected four novel genes (UBC, ARF, LEA26 and 40SRPS8) from our transcriptomic data on

311 graft union healing in cucumber-pumpkin grafted plants, and primers were designed based on

312 the conserved sequence of the genes between cucumber and pumpkin.

313 The $\Delta \mathrm{Ct}$ method, BestKeeper, NormFinder, geNorm, and RefFinderare five software programs

314 and methods that are commonly used to identify reference genes (Scarabel et al., 2017; Duan et

315 al., 2017). In our study, two genes were sufficient for reliable normalization when all samples

316 were subjected to geNorm analysis (Fig 3). The $\Delta \mathrm{Ct}$ method, NormFinder, geNorm, and 
317 RefFinder programs all suggested the same least suitable reference genes, but differed from the

318

319

320

321

322

323

324

325

326

327

328

329

330

331

332

333

334

335

336

337

338

339

340

341

342

343

344

345

346

347

348

349

350

351

352

353

354

355

356

rankings obtained by BestKeeper. For instance, F-Box was ranked as the least stable gene in Cos samples by the $\triangle \mathrm{Ct}$ method, NormFinder, geNorm, and RefFinder programs analysis, while BestKeeper identified $U B C$ as the lowest stability gene in the Cos samples. This different result for different methods is consistent with the result of a study by Niu et al. (2017) where the rankings obtained by BestKeeper were also different from those obtained by geNorm and NormFinder. The most suitable reference genes differed between the five algorithms. Six of the traditional reference genes (TIP41, CACS, ARF, UBC, CYP and $P P 2 A$ ) and two novel reference genes (LEA26 and 40SRPS8) were identified as the optimal reference genes in different samples using different algorithms for analysis. The comprehensive evaluation by RefFinder used data from the other four computational methods, and this ranking showed that TIP41, CACS, TUA, and $L E A 26$ were the most suitable reference genes in different samples of cucumber, pumpkin, and cucumber-pumpkin grafted plants.

TIP41 is a tonoplast intrinsic protein that functions as a PPA2 activator in plants, and has been identified as a suitable reference gene in Cucumis sativus (Wan et al., 2010), Cichorium intybus (Delporte et al., 2015), and Papaver rhoeas (Scarabel et al., 2017). In our study, TIP41 was a stable reference gene in cucumber, pumpkin, and at the graft union of different varieties of grafted cucumber plants, but TIP41 was ranked as a gene with relatively lower stable in the Gos samples (Table 2). This may suggest that grafted plants are different from the nongraft scion and rootstock at the molecular level. Surprisingly, TIP4I was ranked as the least stable reference gene in the graft union of cucumber-pumpkin grafted plants at low temperatures. Importantly, reference gene stability can vary under different experimental treatments (Bustin et al., 2005). Reid et al. (2006) showed that TIP41 is an inadequate reference gene during berry development. Similarly, TUA was regarded as the most stable reference gene in the graft union under cold stress, but was ranked as the least suitable reference gene in pumpkin organs by RefFinder analysis (Table 2). In cucumber, TUA is a highly stable gene when different tissues were treated with abscisic acid, salicylic acid, and methyl jasmonic acid (Wan et al., 2010), however, TUA was limited as a stable reference gene in cucumber under conditions of salt, osmotic stress, and high or low temperature (Wan et al., 2010; Migocka and Papierniak, 2011). CACS encodes the clathrin adaptor complex subunit, which links clathrin to receptors in vesicles (Migocka and Papierniak, 2011). As this gene participates in a basic intracellular transport process, CACS has been used as a reference gene at different developmental stages and under varying environmental conditions in Arabidopsis thaliana (Czechowski et al., 2005), buckwheat (Fagopyrum esculentum) (Demidenko et al. 2011), and lettuce (Lactuca sativa) (Borowski et al., 2014). In cucumber, $C A C S$ was ranked as the best reference gene under different nitrogen nutrition conditions (Warzybok and Migocka, 2013), heavy metal stress, and on deprivation and/or readdition of different nutrients (N, C, P, and S) (Migocka and Papierniak, 2011). One of the novel reference genes, LEA26 (Late Embryogenesis Abundant protein 26), is related to abiotic stress tolerance, especially desiccation tolerance in Arabidopsis. LEA26 has not been evaluated as a reference gene in any species (Dang et al., 2014). In our study, LEA26 was the most stable 
357

358

359

360

361

362

363

364

365

366

367

368

369

370

371

372

373

374

375

376

377

378

379

380

381

382

383

384

385

386

387

388

389

390

391

392

393

reference gene in the Ggs. However, LEA26 was also identified as the lowest stable in the GLgs samples by BestKeeper analysis and exhibited relatively lower stability in the Pos sample. Overall, the results showed it was necessary to validate reliable reference genes prior to qRTPCR analysis under detailed experimental conditions.

To validate use of the identified reference genes as control genes with unchanging expression levels, the expression levels of csaRUL, csaCYCD3;1, cmoRUL, and cmoPIN in the cucumberpumpkin graft union healing process were normalized by the two most stable reference genes and the least stable gene. The results showed that $L E A 26$ and $A R F$ may be the best candidate reference genes for the normalization of gene expression in the graft union healing process. The use of inappropriate reference genes may lead to inaccurate results, making it extremely important to identity suitable reference genes to increase the reliability of qRT-PCR data for target gene expression.

\section{Conclusions}

To our knowledge, this is the first report of the simultaneous use of cucumber, pumpkin and their grafted plants as samples to identify optimal candidate reference genes. Twelve candidate reference genes were validated in different organs, conditions, species of cucumber, pumpkin and their grafted plants using five software tools-the $\Delta \mathrm{Ct}$ method, BestKeeper, NormFinder, geNorm and RefFinder. The results showed that TIP4I and CACS showed the most stable expression in different cucumber organs, TIP4I and $P P 2 A$ were the optimal reference genes in pumpkin organs, TUA and RPL36Aa were the most stable in the graft union under cold stress, $L E A 26$ and $A R F$ showed the most stable expression in the graft union during the healing process, TIP41 and PP2A were the most stable across different varieties of cucumber-pumpkin grafted plants, and $C A C S$ and $40 S R P S 8$ were the most stable in all grafted cucumber samples. Our analysis showed that two genes are sufficient for reliable normalization when all samples are considered. This work should facilitate future studies on gene function and molecular mechanisms in cucumber-pumpkin grafted plants and other closely related species.

\section{Acknowledgements}

We are particularly appreciated to MengmengDuan, Jinglei Wang,and other members in our research group for their kind suggestions to perfect the experiment.

\section{References}

Ahn, S. J., Im, Y. J., Chung, G. C., Cho, B. H., and Suh, S. R. (1999). Physiological responses of grafted-cucumber leaves and rootstock roots affected by low root temperature. Scientia Horticulturae 81, 397-408. Doi:10.1016/S0304-4238(99)00042-4. Andersen, C. L., Jensen, J. L., Ørntoft, T. F. (2004). Normalization of real-time quantitative reverse transcription-PCR data: a model-based variance estimation approach to identify genes suited for normalization, applied to bladder and colon cancer data sets. Cancer Research 64, 5245-5250. Doi:10.1158/0008-5472.CAN-04-0496. 
394 Berg, J. A., Appiano, M., Martínez, M. S., Hermans, F. W., Vriezen, W. H., Visser, R. G., 395 Bai, L. Y., Schouten, H. J. (2015). A transposable element insertion in the susceptibility gene 396 CsaMLO8 results in hypocotyl resistance to powdery mildew in cucumber. BMC Plant 397 Biology 15, 243. Doi:10.1186/s12870-015-0635-x.

398 Borowski, J. M., Galli, V., da Silva Messias, R., Perin, E. C., Buss, J. H., e Silva, S. D. D. A., 399 Rombaldi, C. V. (2014). Selection of candidate reference genes for real-time PCR studies in 400 lettuce under abiotic stresses. Planta 239(6), 1187-1200. Doi:10.1007/s00425-014-2041-2.

401 Bustin, S. A. (2002). Quantification of mRNA using real-time reverse transcription PCR (RT402 PCR): trends and problems. Journal Molecular Endocrinology 29, 23-39.

403 Doi:10.1677/jme.0.0290023.

404 Bustin, S. A., Benes, V., Nolan, T., and Pfaffl, M. W. (2005). Quantitative real-time RT-PCR405 a perspective. Journal of Molecular Endocrinology 34, 597-601. Doi: 10.1677/jme.1.01755.

406 Bustin, S. A., Benes, V., Garson, J. A., Hellemans, J., Huggett, J., Kubista, M.,

407 Vandesompele, J. (2009). The MIQE Guidelines: Minimum Information for Publication of 408 Quantitative Real-Time PCR Experiments. Clinical chemistry 55, 611-622.

409 Doi:10.1373/clinchem.

410 Cao, H., Wang, L., Nawaz, M. A., Niu, M., Sun, J., Xie, J., Kong, Q., Huang, Y., Cheng, F., 411 Bie, Z. (2017). Ectopic expression of pumpkin nac transcription factor cmnac 1 improves 412 multiple abiotic stress tolerance in Arabidopsis. Frontiers in Plant Science 8, 2052.

413 Doi:10.3389/fpls.2017.02052.

414 Czechowski, T., Stitt, M., Altmann, T., Udvardi, M. K., Scheible, W. R. (2005). Genome415 wide identification and testing of superior reference genes for transcript normalization in 416 Arabidopsis. Plant Physiology 139, 5-17. Doi:10.1104/pp.105.063743.

417 Dang, N. X., Popova, A. V., Hundertmark, M., and Hincha, D. K. (2014). Functional 418 characterization of selected $L E A$ proteins from Arabidopsis thaliana in yeast and in 419 vitro. Planta240, 325-336. Doi:10.1007/s00425-014-2089-z.

420 De Jonge, H. J., Fehrmann, R. S., de Bont, E. S., Hofstra, R. M., Gerbens, F., Kamps, W. 421 A., De Vries, E. G., Van der Zee, A. G., TeMeerman, G. J., ArjaterElst. (2007). Evidence 422 based selection of housekeeping genes. PLOS ONE 2 e898. Doi:10.1371/journal.pone.0000898.

423 Delporte, M., Legrand, G., Hilbert, J. L., Gagneul, D. (2015). Selection and validation of reference genes for quantitative real-time PCR analysis of gene expression in Cichoriumintybus. Frontiers in Plant Science 6, 651. Doi:10.3389/fpls.2015.00651.

427 Demidenko, N.V., Logacheva, M. D., Penin, A. A. (2011). Selection and validation of

428

429

430

431

432

433 reference genes for quantitative real-time PCR in buckwheat (Fagopyrumesculentum) based on transcriptome sequence data. PLoS ONE 6, e19434. Doi:10.1371/journal.pone.0019434.

Derveaux, S., Vandesompele, J., Hellemans, J. (2010). How to do successful gene expression analysis using real-time PCR. Methods 50, 227-230. Doi:10.1016/j.ymeth.2009.11.001.

Duan, M., Wang, J., Zhang, X., Yang, H., Wang, H., Qiu, Y., Li, X. (2017). Identification of optimal reference genes for expression analysis in Radish (Raphanus sativus L.) and its relatives based on expression stability. Frontiers in Plant Science 8, 1605. Doi:10.3389/fpls.2017.01605. 
434 Guénin, S., Mauriat, M., Pelloux, J., Van Wuytswinkel, O., Bellini, C., Gutierrez, L. (2009).

435 Normalization of qRT-PCR data: the necessity of adopting a systematic, experimental

436 conditions-specific, validation of references. Journal of Experimental Botany 60, 487-493.

437 Doi:10.1093/jxb/ern305.

438 Haroldsen, V., Szczerba, M. W., Aktas, H., Lopez, J., Odias, M. J., Chi-Ham, C. L.,

439 Labavitch, J. M., Bennett, A. B., Powell, A. L. (2012). Mobility of transgenic nucleic acids and 440 proteins within grafted rootstocks for agricultural improvement. Frontiers in Plant Science 3, 39.

441 Doi:10.3389/fpls.2012.00039.

442 Huang, S., Li, R., Zhang, Z., Li, L., Gu, X., Fan, W., Lucas, W.,Wang, X., Xie, B., Ni, B.,

443 Ren, Y., Zhu, H., Li, J., Lin, K., Jin, W., Fei, Z., Li, G., Staub, J., Kilian, A., van der

444 Vossen, E., Wu, Y., Guo, J., He, J., Jia, Z., Ren, Y., Tian, G., Lu, Y., Ruan, J., Qian, W.,

445 Wang, M., Huang, Q., Li, B., Xuan, Z., Cao, J., Wu, Z., Zhang, J., Cai, Q., Bai, Y., Zhao,

446 Y., Han, Y., Li, Y., Li, X., Wang, S., Shi, Q., Liu, S., Cho, W., Kim, J., Xu, Y., Heller-

447 Uszynska, K., Miao, H., Cheng, Z., Zhang, S., Wu, J., Yang, Y., Kang, H., Li, M., Liang, H., 448 Ren, X., Shi, Z., Wen, M., Jian, M., Yang, H., Zhang, G., Yang, Z., Chen, R., Liu, S., Li, J., 449 Ma, L., Liu, H., Zhou, Y., Zhao, J., Fang, X., Li, G., Fang, L., Li, Y., Liu, D., Zheng, H., 450 Zhang, Y., Qin, Y., Li, Z., Yang, G., Yang, S.,Bolund, L., Kristiansen, K., Zheng, H., Li, S., 451 Zhang, X., Yang, H., Wang, J., Sun, R., Zhang, B., Jiang, S., Wang, J., Du, Y., Li, S.(2009).

452 The genome of the cucumber, Cucumis sativus L. Nature Genetics41, 1275. Doi:10.1038/ng.475.

453 Huang, Y., Kong, Q. S., Chen, F., Bie, Z. L. (2014). The history, current status and future

454 prospects of vegetable grafting in China. International Symposium on Vegetable Grafting 1086, 455 31-39. Doi:10.17660/ActaHortic.2015.1086.2.

456 Lee, J. M., Kubota, C., Tsao, S. J., Bie, Z., Echevarria, P. H., Morra, L., Oda, M. (2010).

457 Current status of vegetable grafting: Diffusion, grafting techniques, automation. Scientia

458 Horticulturae.127, 93-105. Doi:10.1016/j.scienta.2010.08.003.

459 Li, H., Liu, S. S., Yi, C. Y., Wang, F., Zhou, J., Xia, X. J., Shi, K., Zhao, Y. H., Yu, J. Q.

460 (2014). Hydrogen peroxide mediates abscisic acid-induced HSP 70 accumulation and heat

461 tolerance in grafted cucumber plants. Plant and Cell Environment 37, 2768-2780.

462 Doi:10.1111/pce.12360.

463 Livak, K. J., Schmittgen, T. D. (2001). Analysis of relative gene expression data using real-

464

465 time quantitative PCR and the $2^{-\Delta \Delta \mathrm{CT}}$ method. Methods, 25(4), 402-408.

466

467 Doi:10.1006/meth.2001.1262.

Migocka, M., Papierniak, A. (2011). Identification of suitable reference genes for studying

468 gene expression in cucumber plants subjected to abiotic stress and growth regulators. Molecular

469 Breeding. 28, 343-357. Doi:10.1007/s11032-010-9487-0.

470 Miao, L., Li, S.H., Bai, L.Q., Ali, A., Li, Y.S., He, C.X., Yu, X.C. (2018). Effect of grafting 471 methods on physiological change of graft union formation in cucumber grafted onto bottle gourd rootstock. Scientia Horticulturae 26, 249-256. Doi:10.1016/j.scienta.2018.09.061. 
472 Mohamed, F.H., El-Hamed, K.E.A., Elwan, M.W.M., Hussien, M.N.E. (2014). Evaluation of 473 different grafting methods and rootstocks in watermelon grown in Egypt. Scientia Horticulturae. 474168 (3), 145-150. Doi:10.1016/j.scienta.2014.01.029.

475 Melnyk, C. W. (2017). Connecting the plant vasculature to friend or foe. New

476 Phytologist, 213(4), 1611-1617. Doi:10.1111/nph.14218.

477 Melnyk, C. W., Gabel, A., Hardcastle, T. J., Robinson, S., Miyashima, S., Grosse, I.,

478 Meyerowitz, E. M. (2018). Transcriptome dynamics at arabidopsis graft junctions reveal an 479 intertissue recognition mechanism that activates vascular regeneration. Proceedings of the 480 National Academy of Sciences of the United States of America, 115(10), E2447.

481 Doi:10.1073/pnas.1718263115.

482 Niu, X., Chen, M., Huang, X., Chen, H., Tao, A., Xu, J., Qi, J. (2017). Reference gene 483 selection for qRT-PCR normalization analysis in kenaf (Hibiscus cannabinus L.) under abiotic 484 stress and hormonal stimuli. Frontiers in Plant Science 8, 771. Doi:10.3389/fpls.2017.00771 485 Nolan, T., Hands, R. E., Bustin, S. A. (2006). Quantification of mRNA using real-time RT486 PCR. Nature Protocols 1, 1559. Doi:10.1038/nprot.2006.236.

487 Obrero, Á., Die, J. V., Román, B., Gómez, P., Nadal, S., González-Verdejo, C. I. (2011). 488 Selection of reference genes for gene expression studies in zucchini (Cucurbita pepo) using 489 qPCR. Journal of Agricutural Food Chemistry 59, 5402-5411. Doi:10.1021/jf200689r.

490 Pfaffl, M. W., Tichopad, A., Prgomet, C., Neuvians, T. P. (2004). Determination of stable 491 housekeeping genes, differentially regulated target genes and sample integrity: BestKeeper492 Excel-based tool using pair-wise correlations. Biotechnology letters 26, 509-515. 493 Doi:10.1023/B:BILE.0000019559.84305.47.

494 Reda, M., Golicka, A., Kabała, K., Janicka, M. (2018). Involvement of NR and PM-NR in NO 495 biosynthesis in cucumber plants subjected to salt stress. Plant Science. 267, 55-64.

496 Doi:10.1016/j.plantsci.2017.11.004.

497 Reid, K. E., Olsson, N., Schlosser, J., Peng, F., Lund, S. T. (2006). An optimized grapevine 498 RNA isolation procedure and statistical determination of reference genes for real-time RT-PCR 499 during berry development. BMC Plant Boilogy 6, 27. Doi:10.1186/1471-2229-6-27.

500 Saddhe, A. A., Malvankar, M. R., Kumar, K. (2018). Selection of reference genes for 501 quantitative real-time PCR analysis in halophytic plant Rhizophoraapiculata. PeerJ 6, e5226.

502 Doi:10.7717/peerj.5226.

503 Scarabel, L., Milani, A., Panozzo, S., Rasori, A. (2017). Suitable reference genes for accurate 504 gene expression analysis in Papaver rhoeas under 2, 4-D herbicide stress. Pesticide biochemistry 505 and physiology, 143, 66-72. Doi:10.1016/j.pestbp.2017.09.008.

506 Sgamma, T., Pape, J., Massiah, A., Jackson, S. (2016). Selection of reference genes for 507 diurnal and developmental time-course real-time PCR expression analyses in lettuce. Plant 508 Methods, 12, 21. Doi:10.1186/s13007-016-0121-y.

509 Silver, N., Best, S., Jiang, J., Thein, S. L. (2006). Selection of housekeeping genes for gene 510 expression studies in human reticulocytes using real-time PCR. BMC Molecular Biology 7, 33.

511 Doi:10.1186/1471-2199-7-33. 
512 Sun, H., Wu, S., Zhang, G., Jiao, C., Guo, S., Ren, Y., Zhang, J., Zhang, H.,Gong, G., Jia, 513 Z., Zhang, F., Tian, J., Lucas, W., Doyle, J., Li, H., Fei, Z., Xu, Y. (2017). Karyotype stability 514 and unbiased fractionation in the paleo-allotetraploid Cucurbita genomes. Molecular Plant 10, 515 1293-1306. Doi:10.1016/j.molp.2017.09.003.

516 Tashiro, R. M., Philips, J. G., Winefield, C. S. (2016). Identification of suitable grapevine 517 reference genes for qRT-PCR derived from heterologous species. Molecular Genetics and 518 Genomics, 291(1), 483-492. Doi:10.1007/s00438-015-1081-z.

519 Van, H., Zhao, Z., Qian, C., Sui, Y., Malik, A. A., Chen, J. (2010). Selection of appropriate 520 reference genes for gene expression studies by quantitative real-time polymerase chain reaction 521 in cucumber. Analytical Biochemitry 399, 257-261. Doi:10.1016/j.ab.2009.12.008.

522 Vandesompele, J., De Preter, K., Pattyn, F., Poppe, B., Van Roy, N., De Paepe, A., 523 Speleman, F. (2002). Accurate normalization of real-time quantitative RT-PCR data by 524 geometric averaging of multiple internal control genes. Genome Biology 3, research0034-1. 525 Doi:10.1186/gb-2002-3-7-research0034.

526 Warzybok, A., Migocka, M. (2013). Reliable reference genes for normalization of gene 527 expression in cucumber grown under different nitrogen nutrition. PLoS ONE 8, e72887.

528 Doi:10.1371/journal.pone.0072887.

529 


\section{Figure 1}

Graft union of cucumber-pumpkin grafted plants.

Red box indicates graft union of cucumber-pumpkin grafted plant, and the upper is scion-cucumber, the lower part is rootstock-pumpkin. A cucumber cultivar (Zhongnong No.26)was used as the scion, a pumpkin cultivar (Jinxinzhen No.5) was used as the rootstock. Graft union of cucumber-pumpkin grafted plants $20 \mathrm{~d}$ after grafting. Red box indicates graft union of cucumber-pumpkin grafted plant, and the upper is scioncucumber, the lower part is rootstock-pumpkin.

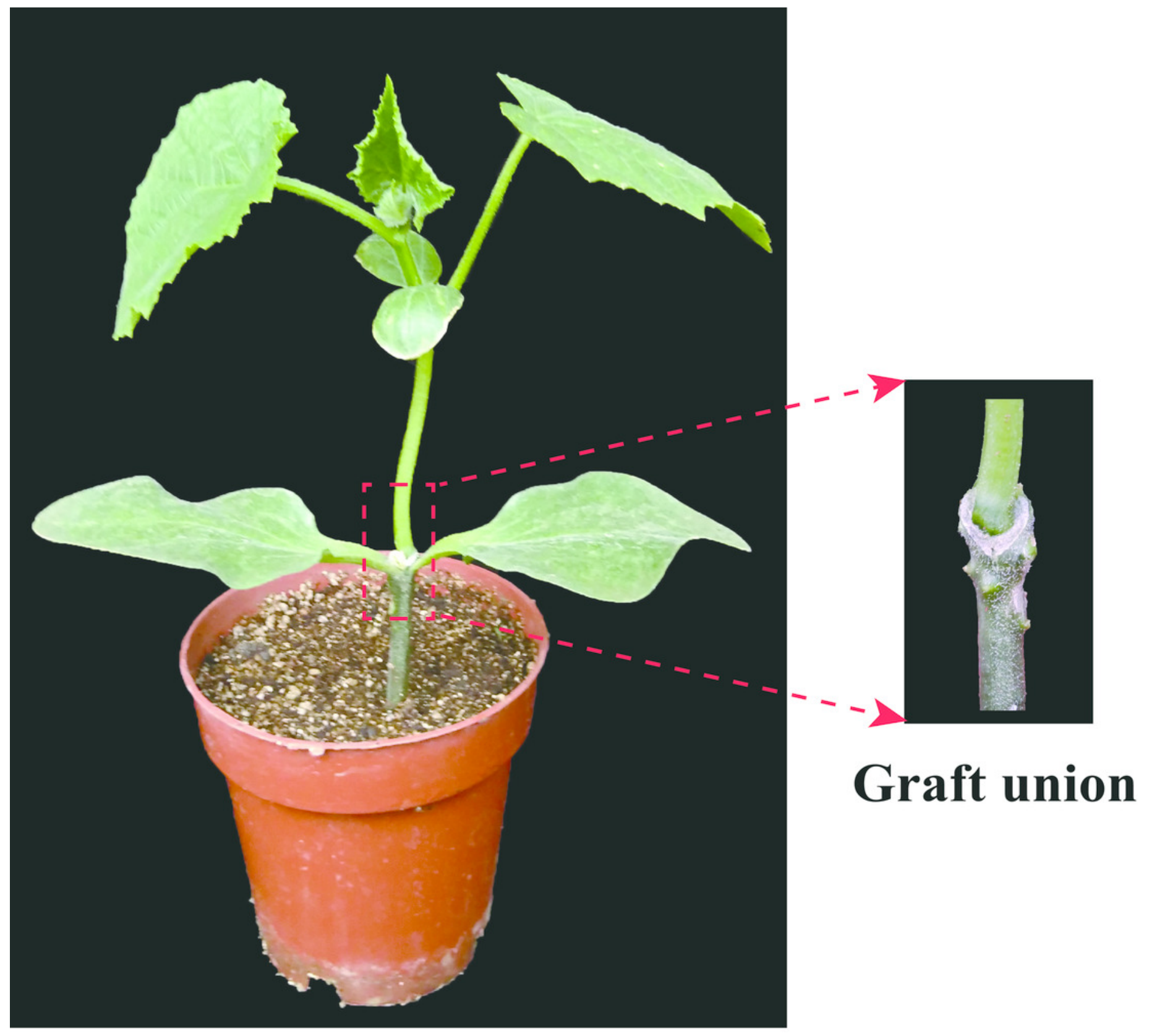




\section{Figure 2 (on next page)}

Ct values of 12 candidate reference genes from the qRT-PCR analysis in all samples.

Boxplots show the 25th and 75th percentiles, means, and outliers. For each reference gene, the line inside the box is the means. The top and bottom line of the box are 75th and 25th percentiles. The circles above or below the box are outliers. 
35

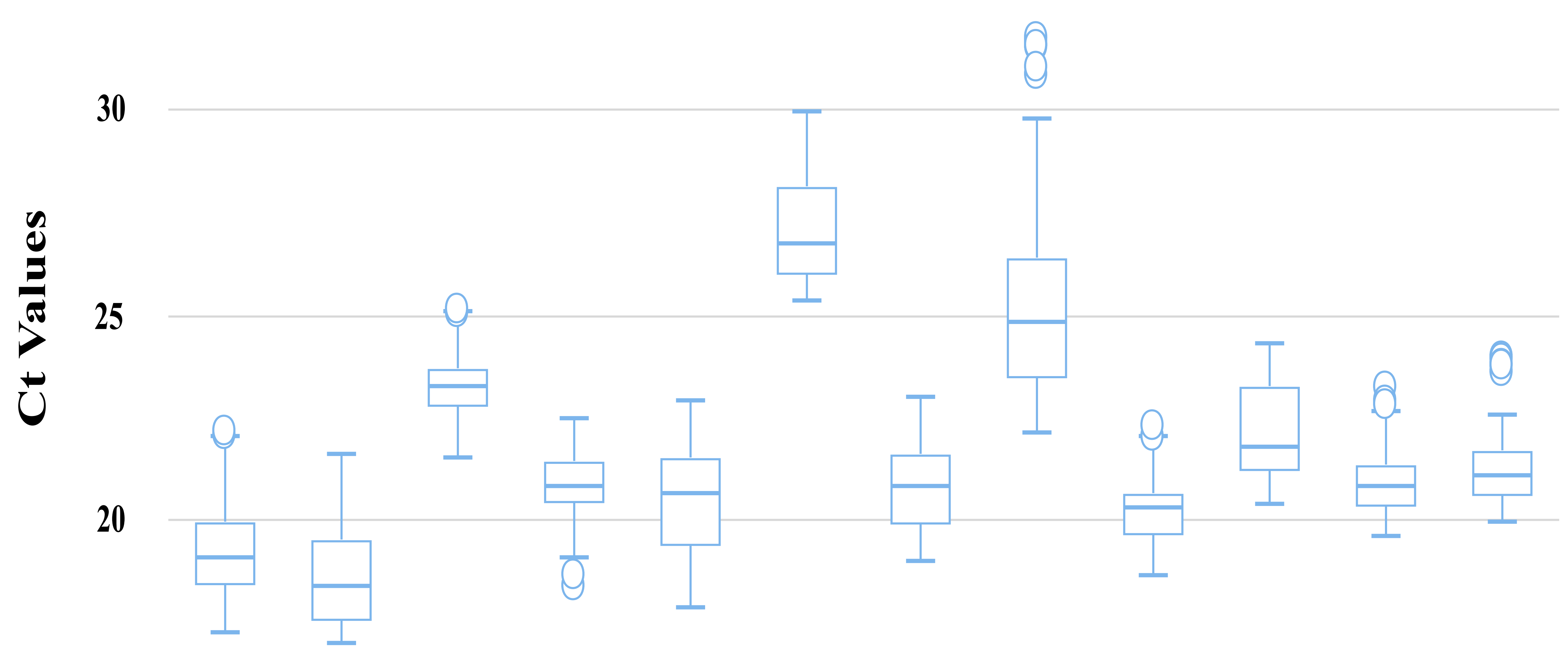

15 ACT CYP CASA TUA TIP41 F-Box RPL36Aa PP2A UBC ARF LEA26 40SRPS8 


\section{Figure 3 (on next page)}

Determination of the optimal number of reference genes.

Pairwise variation $\mathrm{Vn} / \mathrm{Vn}+1$ values caculated by geNorm software. A cut-off of 0.15 ( $\mathrm{Vn}$ value) is usually applied. V1 to V12 stand for the variation in candidate reference genes ranked based on their stability, which V1 is the variation for the most stable and V12 is the least stable gene. Cos: organs of cucumber; Pos: organs of pumpkin; Gos: organs of cucumberpumpkin; GLgs: graft union of cucumber-pumpkin under low temperature stress; Ggs: graft union of cucumber-pumpkin in healing process; Ggvs: graft union of different varieties of cucumber-pumpkin; GosAll: all grafted cucumber samples; All, all samples. 
$\begin{array}{lllllllllllll}0.25 & V_{2 / 3} & \square V_{3 / 4} & \square V_{4 / 5} & \square V_{5 / 6} & \square V_{6 / 7} & \square V_{7 / 8} & \square V_{8 / 9} & \square V_{9 / 10} & \square V_{10 / 11} & \square V_{11 / 12}\end{array}$

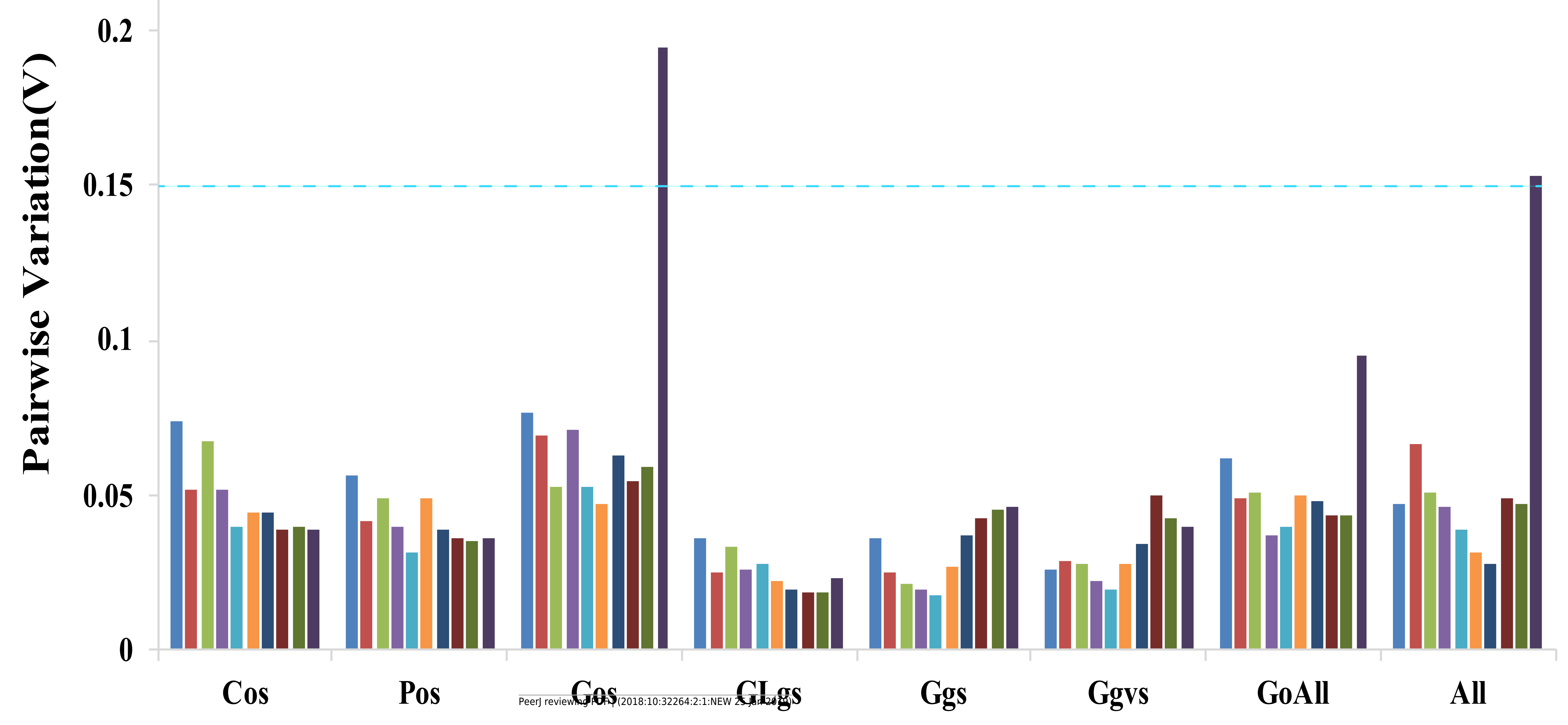


Figure 4 (on next page)

Relative expression levels of $\operatorname{csaCYCD} 3 ; 1(\mathrm{~A}), \mathrm{cmoPIN}(\mathrm{B}), \operatorname{csaRUL}(\mathrm{C}), \mathrm{CmoRUL}(\mathrm{D})$ using different reference genes at the graft union at $0,1,3,6,9$, 15d after grafting.

The two most suitable reference genes (LEA, ARF), their combination (LEA26+ARF), and the least stable reference gene (PP2A) by RefFinder analysis were used for expression normalization. Bars represent the means and standard deviations of three biological replicates. 


\section{Table $\mathbf{1}$ (on next page)}

Description of the candidate references, primer sequences and RT-PCR amplification efficiencies in cucumber, pumpkin, and grafted cucumber/pumpkin.

Description of the candidate references, primer sequences and RT-PCR amplification efficiencies in cucumber, pumpkin, and grafted cucumber/pumpkin. 
1 Table 1 Description of the candidate references, primer sequences and RT-PCR amplification efficiencies in cucumber, pumpkin, and grafted 2 cucumber/pumpkin.

\begin{tabular}{|c|c|c|c|c|c|c|c|c|c|c|}
\hline \multirow{2}{*}{ Gene } & \multirow{2}{*}{$\begin{array}{l}\text { Accession } \\
\text { number } \\
\text { (NCBI) }\end{array}$} & \multirow{2}{*}{ Annotation } & \multirow{2}{*}{$\begin{array}{l}\text { Gene ID in } \\
\text { cucumber }\end{array}$} & \multirow{2}{*}{ Forward primer (5'-3') } & \multirow{2}{*}{ Reverser primer (5'-3') } & \multirow{2}{*}{$\begin{array}{l}\text { Amplification } \\
\text { length }\end{array}$} & \multirow{2}{*}{$\operatorname{Tm}\left({ }^{\circ} \mathrm{C}\right)$} & \multicolumn{3}{|c|}{ RT-qPCR efficiency } \\
\hline & & & & & & & & Cucumber & Pumpkin & Cucumber/pumpkin \\
\hline ACT & $\mathrm{AB} 010922$ & Actin (ACT) & Csa6G484600 & TCTCCGTTTGGACCTTGC & ATTTCCCGTTCGGCAGT & 99 & 83.2 & 0.88 & 1.05 & 0.86 \\
\hline CYP & AY942800 & Cyclophilin & Csa7G009740 & TTTCATGTGCCAGGGAGG & AGCCAATCGGTCTTAGCG & 189 & 88.1 & 0.99 & 1.05 & 1.05 \\
\hline CACS & GW881874 & $\begin{array}{l}\text { Clathrin adaptor complex } \\
\text { subunit (CACS) }\end{array}$ & Csa3G902930 & TGGGAAGATTCTTATGAAGTGC & CTCGTCAAATTTACACATTGGT & 171 & 84.2 & 1.02 & 0.95 & 1.00 \\
\hline TUA & AJ715498 & Alpha-tubulin (TUA) & Csa4G000580 & TCAGCGGCAAGGAAGATG & GCGGATTCTGTCCAAGCA & 92 & 83.7 & 1.03 & 0.87 & 1.00 \\
\hline TIP41 & GW881871 & TIP41-like family protein & Csa7G071610 & TGGGAGGATTGCGAGGAGA & AAGTGATATGCCATTGTCAGC & 117 & 81.6 & 0.97 & 1.08 & 1.13 \\
\hline F-BOX & GW881870 & $\begin{array}{l}\text { F-box/kelch-repeat } \\
\text { protein }\end{array}$ & Csa5G642160 & TGGTTCATCTGGTGGTCTTG & TTAGCTGCCTCTGCTGATTG & 131 & 84.3 & 1.08 & 0.93 & 0.90 \\
\hline PRL36Aa & HM594174 & $\begin{array}{l}\text { 60S ribosomal protein } \\
\mathrm{L} 36 \mathrm{a} / \mathrm{L} 44\end{array}$ & Csa3G653380 & AAGATAGTCTTGCTGCACAGGG & AACACGGGCTTGGTTTGA & 79 & 83.3 & 0.97 & 0.95 & 0.99 \\
\hline PP2A & HM594171 & $\begin{array}{l}\text { protein phosphatase } 2 \mathrm{~A} \\
\text { regulatory subunit } \mathrm{A}\end{array}$ & Csa5G608520 & GAAGCTGTAGGACCTGAACCA & AGCCGCTGCAATACGAAC & 96 & 84.6 & 1.07 & 1.13 & 0.91 \\
\hline $\mathrm{UBC}$ & - & - & Csa3G358610 & GTCACCATTCATTTTCCTCCG & GGGCTCCACTGCTCTTTCA & 131 & 83.9 & 1.04 & 1.07 & 1.12 \\
\hline ARF & - & - & Csa5G524710 & CTGCTGGAAAGACCACGAT & GACCACCAACATCCCATACA & 132 & 83.5 & 1.02 & 1.12 & 1.03 \\
\hline LEA26 & - & - & Csa2G151040 & CGTTGACTTACCCATCACCTTC & GCGTGTAGTACCACCCTCTTTA & 163 & 85.5 & 1.00 & 1.06 & 0.98 \\
\hline 40SRPS8 & - & - & Csa6G382970 & ACTCGACACTGGAAACTACTCG & CCTGAACAACGGCACTCTT & 134 & 85.1 & 0.87 & 1.03 & 1.01 \\
\hline
\end{tabular}

3 


\section{Table 2 (on next page)}

Overall ranking of the candidate reference genes in eight groups by $\Delta$ Ctmethod, BestKeeper, NormFinder, geNorm, and RefFinder.

Overall ranking of the candidate reference genes in eight groups by $\Delta$ Ctmethod, BestKeeper, NormFinder, geNorm, and RefFinder. 
1 Table 2 Overall ranking of the candidate reference genes in eight groups by $\Delta \mathrm{Ct}$ method, BestKeeper, NormFinder, geNorm, and RefFinder.

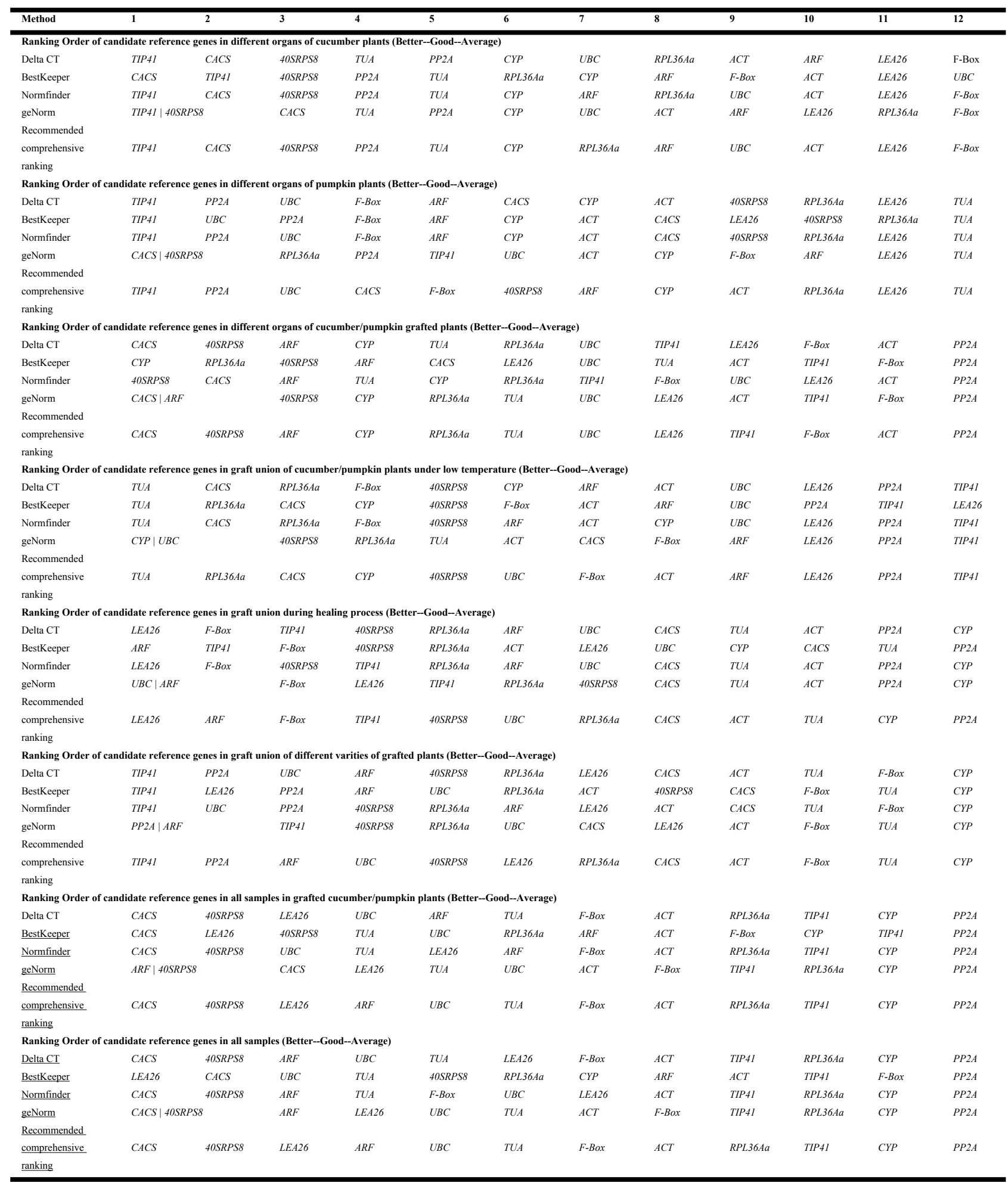

